\title{
THE TECHNIQUE OF STAINING LEPROSY BACILLI IN SMEARS.
}

\author{
by A. R. DAvison, M.R.C.S (Eng.), L.R.C.P. (Lond.) \\ Westfort Institution, Pretoria, South Africa.
}

In the Leprosy Review' R. Rhodes-Jones described his modified technique for staining leprosy bacilli in smears. I noted he did not use alcohol in his decolorizer and used toluidin blue as a counterstain. I have previously"2 drawn attention to the danger of inadequate decolorization when using acid alone for a short period. We have now come to the conclusion that acid alone is an inadequate decolorizer and our present technique is to use $3 \% \mathrm{HCl}$ in S.V.R. for 15 minutes.

We have occasionally found partially acid-fast diphtheroids in cases of chronic acne. So from patient No. 8992 (Plate I) we took 12

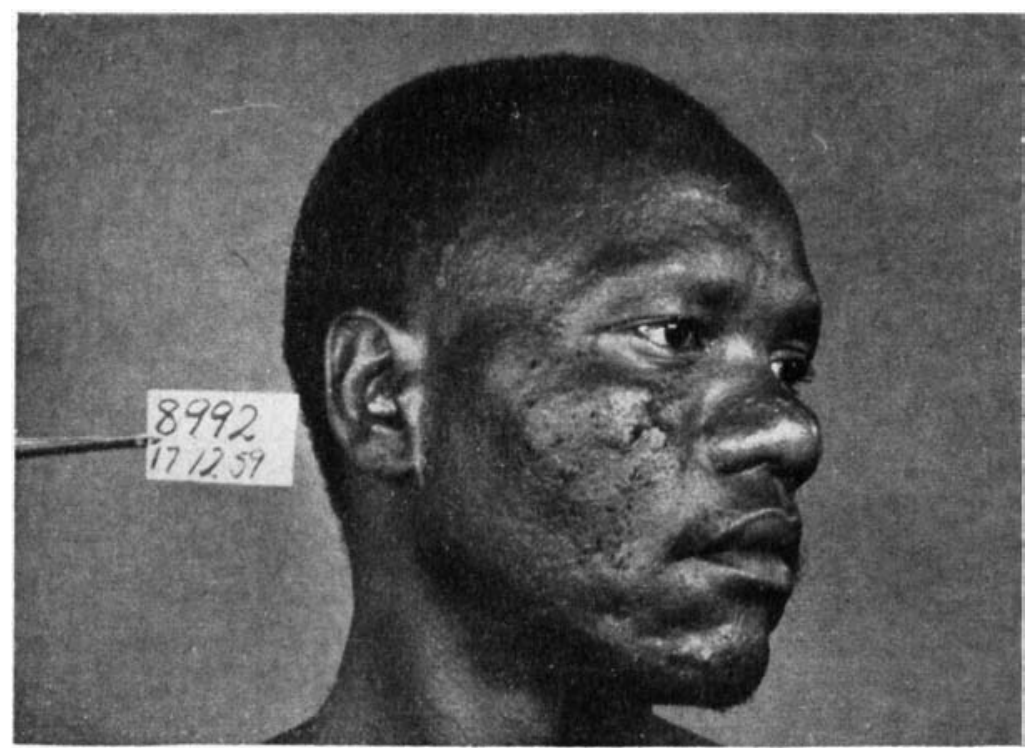

skin smears. The slides were numbered from 1 to 12 . The first six slides were stained in the usual manner but slides 1, 2 and 4 were purposely under-decolorized. The first three were decolorized by $3 \%$ $\mathrm{HCl}$ in S.V.R. and the other three by $5 \%$ sulphuric acid. They were counterstained with a saturated watery solution of methylene blue for 60 seconds and the excess stain was washed off with water. Our results are tabulated in Table 1.

From the table it will be seen that acid-fast bacilli were found in all slides decolorized by 5\% sulphuric acid and where decolorization was incomplete with $3 \% \mathrm{HCl}$ in S.V.R. 


\section{TABLE I}

Decolorizer

$3 \% \mathrm{HCl}$ in $S V R$.

Slide No. I

2

3.

$5 \%$ Sulphuric Acid

Slide No. 4

5.

6.
Time of

Decolorization

1 minute

5 ,

$15 \quad$,
Results

$3+$

$2+$

Negative

The stained and unstained slides were then posted to $\mathrm{Mr}$. RhodesJones for his comments. In a personal communication he reported that he first found slide 3 to be 1 plus, but on restaining and decolorizing and using methylene blue as a counterstain he obtained the results in Table 2 .

TABLE 2

Slide No.
1
2
3
4
5
6

Method

$1 \mathrm{~min} .3 \% \mathrm{HCl}$ in $\mathrm{SVR}$.

$5 \mathrm{~min} .3 \% \mathrm{HCl}$ in SVR.

$15 \mathrm{~min} .3 \% \mathrm{HDl}$ in SVR.

$1 \mathrm{~min} .5 \%$ Sulphuric acid.

$5 \mathrm{~min} .5 \%$ Sulphuric acid.

$15 \min .5 \%$ Sulphuric acid.
Result

No AFB in 100 fields.

No AFB in 100 fields.

No AFB in 100 fields.

$30 \mathrm{AFB}$ in 100 fields.

5 AFB in 100 flelds.

66 AFB in 100 fields.

He then took the unstained slides, stained them in the usual manner, used both methods of decolorization, but used $0.1 \%$ toluidin blue as a counterstain. He obtained the results detailed in Table 3.

\section{TABLE 3}

\begin{tabular}{crr} 
Slide No. & Method & \multicolumn{1}{c}{ Result } \\
7 & $1 \mathrm{~min} .5 \%$ Sulphuric acid. & 2 bacilli per 100 fields. \\
8 & $5 \mathrm{~min} .5 \%$ Sulphuric acid. & Neg. bacilli per 100 fields. \\
9 & $15 \mathrm{~min} .5 \%$ Sulphuric acid. & Neg. bacilli per 100 fields. \\
10 & $1 \mathrm{~min} .3 \% \mathrm{HCl}$ in SVR. & 3 bacilli per 100 fields. \\
11 & $5 \mathrm{~min} .3 \% \mathrm{HCl}$ in SVR. & Neg. bacilli per 100 fields. \\
12 & $12 \mathrm{~min} .3 \% \mathrm{HCl}$ in SVR. & Neg. bacilli per 100 fields.
\end{tabular}

In his communication to me he makes the interesting statement that "It would therefore seem by my results that if we are counterstaining by either toluidin blue or methylene blue, the diptheroids are effectively masked".

In my view counterstaining is done to make a background to the smear and not to disguise what is on the smear. 
I think these experiments justify our contention that alcohol should be used in the decolorizer.

Our present technique is:-

1. Fix smear over heat, avoid charring.

2. Cover the slide with carbol fuchsin solution. The standard is 1 part of a $10 \%$ solution of basic fuchsin in $90 \%$ alcohol with 9 parts of $5 \%$ solution of carbolic acid crystals in distilled water. Heat until it steams for 10 minutes and wash with water.

3. Decolorize in $3 \% \mathrm{HCl}$ in $95 \%$ alcohol for 15 minutes. Wash with water.

4. Counterstain with a saturated watery solution of methylene blue for 60 seconds.

5. Wash excess stain off with water. Allow to dry.

\section{Acknowledgement}

I have to thank the Secretary for Health, Pretoria, for authority to submit these notes for publication.

\section{References}

1. Rhodes-Jones, R. (1959) Leprosy Review, 30, 4, 1959.

2, Davidson, A. R. (1943) International Journal Lep., 2. Decolorizing of Mycohacterium lepra (49). 